\title{
Effect of Gaining Insurance Coverage on Smoking Cessation in Community Health Centers: A Cohort Study
}

\author{
Steffani R. Bailey, $P h D^{7}$, Megan J. Hoopes, $M P H^{2}$, Miguel Marino, PhD ${ }^{1,4}$, John Heintzman, $M D, M P H^{7}$, \\ Jean P. O'Malley, MPH' ${ }^{4}$, Brigit Hatch, $\mathrm{MD}^{1,2}$, Heather Angier, $\mathrm{MPH}^{7}$, Stephen P. Fortmann, $\mathrm{MD}^{3}$, and \\ Jennifer E. DeVoe, MD DPhil ${ }^{1,2}$
}

'Department of Family Medicine, Oregon Health \& Science University, Portland, OR, USA; ${ }^{2}$ OCHIN, Inc., Portland, OR, USA; ${ }^{3}$ Kaiser Permanente Center for Health Research, Portland, OR, USA; ${ }^{4}$ School of Public Health, Oregon Health \& Science University, Portland, OR, USA.

BACKGROUND: Community health center (CHC) patients have high rates of smoking. Insurance coverage for smoking cessation assistance, such as that mandated by the Affordable Care Act, may aid in smoking cessation in this vulnerable population.

OBJECTIVE: We aimed to determine if uninsured $\mathrm{CHC}$ patients who gain Medicaid coverage experience greater primary care utilization, receive more cessation medication orders, and achieve higher quit rates, compared to continuously uninsured smokers.

DESIGN: Longitudinal observational cohort study using electronic health record data from a network of Oregon CHCs linked to Oregon Medicaid enrollment data.

PATIENTS: Cohort of patients who smoke and who gained Medicaid coverage in 2008-2011 after $\geq 6$ months of being uninsured and with $\geq 1$ smoking assessment in the 24-month follow-up period from the baseline smoking status date. This group was propensity score matched to a cohort of continuously uninsured $\mathrm{CHC}$ patients who smoke ( $n=4140$ matched pairs; 8280 patients).

INTERVENTION: Gaining Medicaid after being uninsured for $\geq 6$ months.

MAIN MEASURES: 'Quit' smoking status (baseline smoking status was 'current every day' or 'some day' and status change to 'former smoker' at a subsequent visit), smoking cessation medication order, and $\geq 6$ documented visits (yes/no variables) at $\geq 1$ smoking status assessment within the 24-month follow-up period.

KEY RESULTS: The newly insured had $40 \%$ increased odds of quitting smoking (aOR = 1.40, 95 \% CI: 1.24, 1.58), nearly triple the odds of having a medication ordered ( $\mathrm{aOR}=2.94,95 \% \mathrm{CI}: 2.61,3.32$ ), and over twice the odds of having $\geq 6$ follow-up visits $(\mathrm{aOR}=2.12,95 \% \mathrm{CI}: 1.94$, 2.32) compared to their uninsured counterparts.

CONCLUSIONS: Newly insured patients had increased odds of quit smoking status over 24 months of follow-up than those who remained uninsured. Providing insurance

This study is registered as an observational study at clinicaltrials.gov (\#NCT02355132).

Electronic supplementary material The online version of this article (doi:10.1007/s11606-016-3781-4) contains supplementary material, which is available to authorized users.

Received April 18, 2016

Revised May 27, 2016

Accepted June 10, 2016

Published online June 21, 2016 coverage to vulnerable populations may have a significant impact on smoking cessation.

KEY WORDS: smoking cessation; insurance coverage; Medicaid; community health centers.

J Gen Intern Med 31(10): 1198-205

DOI: $10.1007 / \mathrm{s} 11606-016-3781-4$

(C) Society of General Internal Medicine 2016

\section{INTRODUCTION}

An estimated 42.1 million individuals in the US are current cigarette smokers, ${ }^{1}$ and approximately 443,000 Americans die from smoking-related illnesses each year. ${ }^{2}$ Between 2005 and 2013, the overall prevalence of smoking decreased from 20.9 to $17.8 \%$; even if this rate of decline continues, adult smoking rates will remain substantially higher than the Healthy People 2020 target goal of $\leq 12 \%$. $^{3}$ Furthermore, several subgroups experience marked disparities: those who live below the federal poverty level (FPL) have higher smoking rates $(29.2 \%)$ than those at or above the FPL $(16.2 \%)^{1}$; among adults under age $65,29.6 \%$ of uninsured and $30.1 \%$ of Medicaid recipients reported smoking in 2012 compared to $15.2 \%$ of those with private insurance. ${ }^{4}$ Additionally, lack of insurance coverage for smoking cessation services has been associated with a lower likelihood of smoking cessation assistance and fewer quit attempts compared to insured individuals. ${ }^{5,6}$

Community health centers $(\mathrm{CHCs})$ provide primary care to medically underserved and vulnerable populations regardless of ability to pay. ${ }^{7}$ Most $\mathrm{CHC}$ patients are uninsured or Medicaid recipients, and have incomes below the FPL. ${ }^{8} \mathrm{CHCs}$ are well positioned to identify patients who smoke and to provide them with smoking cessation assistance. Although evidencebased guidelines for delivering smoking cessation treatments (medications and counseling) in primary care settings constitute standard care ${ }^{9-11}$ and increase the likelihood of smoking cessation, ${ }^{9}$ delivery of these services among healthcare providers remains low. ${ }^{12-15}$ Given the number of smokers served in primary care ${ }^{9}$ and particularly in $\mathrm{CHCs}$, the medical costs of smoking-related illnesses, ${ }^{2}$ and the availability of interventions that are among the most cost-effective in healthcare, ${ }^{16}$ smoking cessation assistance should be a priority for all healthcare providers. 
In January 2014, the Affordable Care Act (ACA) mandated that Medicaid provide insurance coverage for smoking cessation medications. ${ }^{17}$ A recent study found that prior to 2014, only a small percentage of patients with Medicaid utilized smoking cessation medications. ${ }^{18}$ The United States is currently in a position to considerably expand the number of people who can get help to quit smoking via the ACA. Policy leaders hope this coverage will result in increased smoking cessation assistance, leading to an ultimate decrease in smoking prevalence. ${ }^{17}$ Previous research found smoking prevalence dropped by 10 percentage points (38 to $28 \%$ ) after the introduction of new Medicaid-covered tobacco dependence treatment, ${ }^{5}$ and states with the most generous tobacco treatment Medicaid coverage had the highest quit rates. ${ }^{6}$ This previous evidence relied on cross-sectional survey designs, ${ }^{19,20}$ which are subject to limitations (e.g., response bias, low completion rates), or clinical trials that enrolled treatment-seeking patients. ${ }^{21,22}$ The relationship between insurance coverage and smoking cessation may be different among $\mathrm{CHC}$ patients with varying degrees of readiness to quit and among those who recently gained Medicaid insurance.

To build upon previous research, we used electronic health record (EHR) data from a network of Oregon CHCs to test the hypothesis that gaining Medicaid coverage after a period of being uninsured will result in increased quit rates among $\mathrm{CHC}$ patients who smoke, higher rates of ordering smoking cessation medications, and increased primary care utilization compared to smokers who remained uninsured. The EHR facilitates collection of data on patient smoking status at each primary care encounter, enabling longitudinal assessment and comparison of smoking status among insured and uninsured patients. After a freeze on new Medicaid enrollment in the Oregon Health Plan Standard due to a lack of resources, Oregon reopened enrollment in 2008 for a randomly selected subset of low-income adults (ages 19-64 years) who were Oregon residents, US citizens or qualified non-citizens, not categorically eligible for Medicaid based on the federal definition, and uninsured for $\geq 6$ prior months. This allowed many Oregonians to gain public health insurance. ${ }^{23-26}$ During this time period, Oregon's Medicaid program also had comprehensive tobacco treatment coverage (individual and group counseling, nicotine replacement products, bupropion, and varenicline) comparable to that mandated by the $\mathrm{ACA}^{27}$ Therefore, these study findings can be used to elucidate the potential impact of gaining Medicaid insurance on the long-term quit rates and rates of smoking cessation assistance in CHCs, data that cannot yet be ascertained from post-ACA implementation.

\section{METHODS}

\section{Data Sources}

OCHIN EHR. Formerly the Oregon Community Health Information Network but shortened to "OCHIN, Inc." as other states joined, OCHIN is a nonprofit health information technology organization providing a centrally hosted and linked instance of the Epic ${ }^{\circledR}$ EHR to safety net clinic members. EHR data are managed and warehoused centrally at OCHIN, including regular validation and cleaning. ${ }^{28} \mathrm{We}$ used OCHIN EHR data to extract all demographic and encounter information. The EHR presents a discrete data field for smoking status, and the OCHIN workflow requires review of tobacco use status at each primary care encounter. In this field, smoking status (i.e., current every day, current some day, former, or never smoker) can be confirmed or modified, and the reviewed or changed date is saved in the EHR. Tobacco cessation medications were abstracted from EHR medication order data.

Medicaid Enrollment Data. We obtained Medicaid enrollment data from the state of Oregon and linked it to EHR data using a unique Medicaid patient identifier available in both data sets. We used these data to identify Medicaid coverage dates as we have done in prior studies. ${ }^{29,30}$

\section{Study Population}

We identified all CHC patients aged 19-64 years who gained Oregon Medicaid coverage between 2008 and 2011 after being uninsured for $\geq 6$ months and who maintained this insurance for $\geq 6$ months. We then identified a cohort of current smokers among this group who had $\geq 1$ visit at a study clinic with smoking status indicated as 'current every day smoker' or 'current some day smoker' within 6 months of the date they gained Medicaid coverage. From the baseline smoking status date (the encounter date of initial smoking assessment), we identified patients with $\geq 1$ follow-up smoking assessment in the 24-month follow-up period ( $n=1180$ excluded for having no follow-up). Patients were excluded if they were aged $<19$ or $>64$ years, pregnant, died, or had evidence of private insurance or Medicare coverage in the study period. After exclusions, we had a cohort of 5935 current smokers who gained Medicaid.

To identify a matched control group of smokers who did not gain Medicaid, we considered patients who were continuously uninsured throughout the 24-month follow-up period and met the current smoker criteria $(n=9371$ after excluding 6344 smokers with no follow-up). For this uninsured comparison group, the baseline smoking status date was set as the earliest date between 2008 and 2011 at which each patient had an EHR record indicating current smoking status; the follow-up period was 24 months from this date. Because the insured and uninsured groups differed in multiple characteristics, a propensity score matching approach was used to balance potential confounders between groups and reduce bias. ${ }^{31}$ We used logistic regression models to generate propensity scores based on baseline and pre-baseline characteristics including demographics, insurance history, utilization, smoking history (e.g., years smoked at baseline, number of pre-baseline smoking 
assessments), comorbidities, and health center characteristics. We completed a one-to-one nearest neighbor match on propensity scores within a caliper restriction, ${ }^{32}$ and assessed covariate balance for both the full sample and the propensity score-matched sample by computing standardized differences of each variable. We considered covariates with absolute standardized difference $\geq 0.1$ in the propensity scorematched sample to have residual imbalance; none of the variables met this criterion in the matched sample. The final study sample included 4140 matched pairs (8280 patients). Additional detail on propensity score matching and covariate balance is provided in Online Appendix Figure 1. Online Appendix Table 1 compares characteristics of the propensity score matched sample to smokers excluded for having no follow-up smoking assessment $(N=7524)$.

\section{Variables}

Our primary outcome was 'quit' smoking status after the baseline assessment, coded as a binary yes/no variable. A person was identified as 'quit' if baseline smoking status was 'current every day' or 'some day' and status changed to 'former smoker' at a subsequent visit. We also assessed prevalence of having a smoking cessation medication ordered (yes/ no), and analyzed quit smoking status stratified by whether medication was ordered. Medications included bupropion, varenicline, and all nicotine replacement products. As a proxy for utilization of care, we also examined quit smoking status stratified by number of follow-up visits ( $\geq 6$ vs. $<6$ follow-up visits, as six was the median in this study population). Our independent variable was insurance status: comparing patients who gained Medicaid to those who remained continuously uninsured.

\section{Analyses}

We described patient characteristics of both the original and propensity-matched samples. We then described distributions of follow-up visits and smoking assessments, usual source of care (defined as having $\geq 75 \%$ of study encounters at the same clinic), prevalence of smoking cessation medication orders, and changes in smoking status within each group during the study period. Between-group differences were tested using generalized estimating equations (GEE) to account for clustering among propensity score-matched pairs. ${ }^{33} \mathrm{We}$ computed adjusted odds ratios of having a smoking cessation medication ordered, having $\geq 6$ follow-up visits, and quitting smoking using GEE accounting for correlation among propensity score-matched pairs. Models were adjusted for having a usual source of care in the follow-up period; we did not further adjust for any baseline covariates because none were found to have residual imbalance between the groups after propensity score matching (absolute standardized difference $<0.1,{ }^{34}$ see Table 1). We also included each patient's primary $\mathrm{CHC}$ as a fixed effect to adjust for potential differences between health centers. Odds ratios for quit status by medication order and quit status by visit strata were obtained using an interaction term for medication order by study group, and $\geq 6$ visits by study group, respectively. For our GEE models, we assumed a compound symmetry correlation structure and applied a robust sandwich variance estimator to account for possible misspecification. ${ }^{35}$ All analyses were conducted using SAS software, version 9.4 (SAS Institute Inc., Cary, NC). The study was approved prior to data collection by the Oregon Health \& Science University Institutional Review Board.

\section{RESULTS}

After propensity score matching, the gained Medicaid and uninsured groups were balanced on all baseline demographic variables (absolute standardized difference $<0.1$, Table 1 ). The sample was $49 \%$ male, had a median age of 42 years at baseline, and $81 \%$ had incomes $\leq 100 \%$ of FPL. Approximately $15 \%$ of patients were Hispanic or non-white race. Marginally more patients in the group that gained Medicaid had a history of Medicaid coverage prior to the 6 months of being uninsured (43.7 vs. $39.0 \%$ of uninsured). Chronic conditions were common in both groups: overall, $15.5 \%$ of patients had diagnosed hypertension, $10.2 \%$ had asthma/ COPD, $6.2 \%$ had diabetes, and $9.7 \%$ had $\geq 2$ active chronic conditions as of the baseline date. Approximately $23 \%$ of patients had smoked for $>20$ years at baseline, and $96 \%$ were everyday smokers.

Patients who gained Medicaid had more primary care visits (median $=7$ vs. 5 for uninsured) and more follow-up smoking assessments (median $=4$ vs. 3 , respectively, Table 2 ) over the 24-month follow-up. Over one-quarter of patients who gained Medicaid had a smoking cessation medication ordered (26.9\% vs. $11.5 \%$ of uninsured, $p<0.001)$, and $16.6 \%$ quit smoking in the study period vs. $13.3 \%$ of uninsured, $p<0.001$.

Figure 1 presents adjusted odds ratios (aOR) of quit status and having a smoking cessation medication ordered, as well as the odds of quitting stratified by whether or not medication was ordered and whether or not a patient had $\geq 6$ follow-up visits. The newly insured had $40 \%$ increased odds of quitting compared to their uninsured counterparts $(\mathrm{aOR}=1.40,95 \% \mathrm{CI}: 1.24,1.58 ; 16.6 \%$ vs. $13.3 \%$, respectively). The odds of having medication ordered were almost three times higher for patients who gained Medicaid relative to the uninsured cohort $(\mathrm{aOR}=$ 2.94, $95 \%$ CI: 2.61, 3.32), and the newly insured had twice the odds of having $\geq 6$ follow-up visits than the continuously uninsured (aOR $=2.12,95 \% \mathrm{CI}: 1.94,2.32$ ). Among patients without a smoking medication ordered, the gained Medicaid group had significantly higher odds of quitting compared to the group of uninsured smokers $(\mathrm{aOR}=1.23,95 \% \mathrm{CI}: 1.06-1.41)$; among those with medication ordered, the odds of quitting was also higher for those who gained Medicaid, but the difference was not 
Table 1. Characteristics of Study Sample of CHC Patients Who Reported Being Current Smokers at Baseline

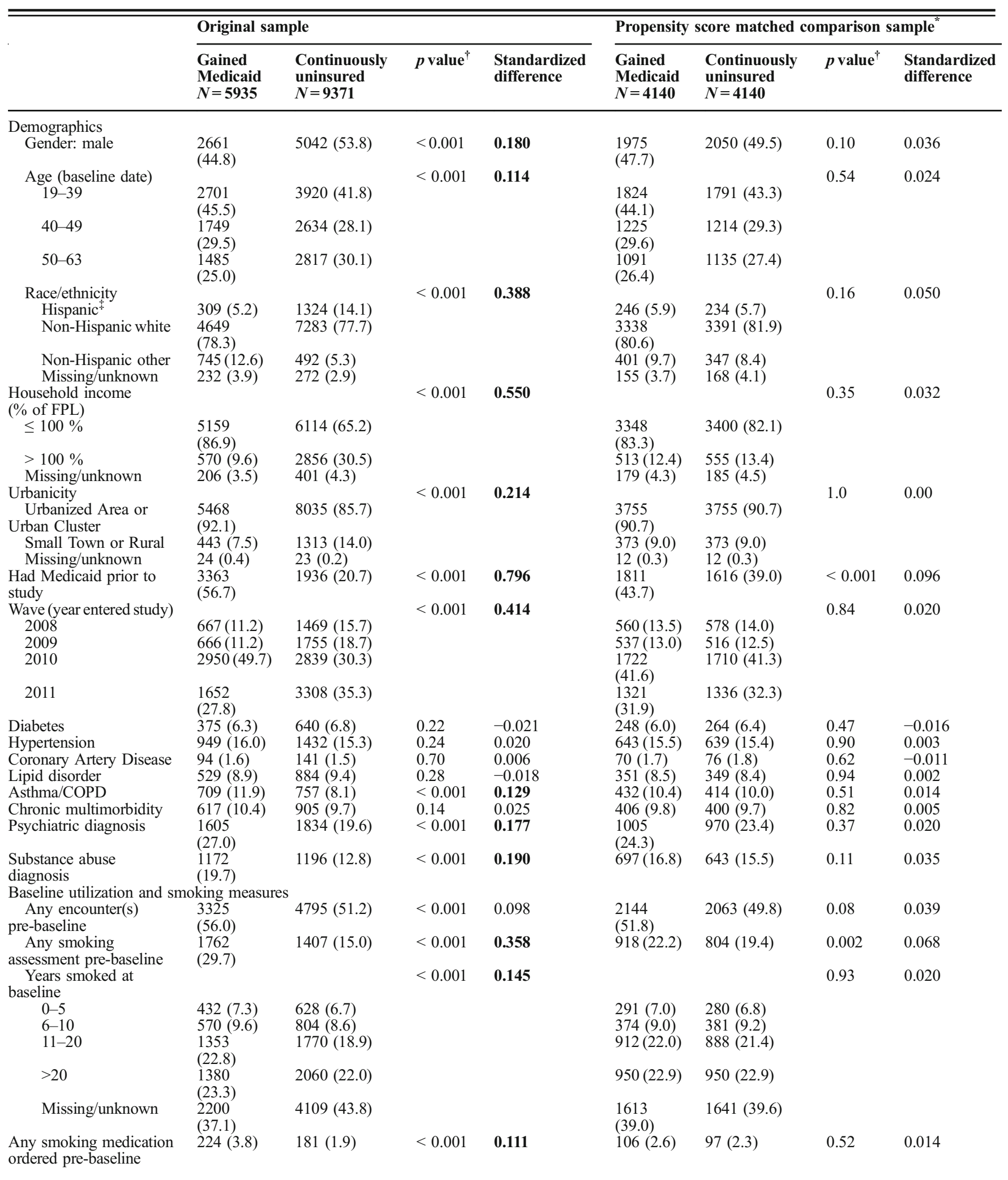


Table 1.. (continued)

\begin{tabular}{|c|c|c|c|c|c|c|c|c|}
\hline \multirow{2}{*}{-} & \multicolumn{4}{|c|}{ Original sample } & \multicolumn{4}{|c|}{ Propensity score matched comparison sample $^{*}$} \\
\hline & $\begin{array}{l}\text { Gained } \\
\text { Medicaid } \\
N=5935\end{array}$ & $\begin{array}{l}\text { Continuously } \\
\text { uninsured } \\
N=9371\end{array}$ & $p$ value ${ }^{\dagger}$ & $\begin{array}{l}\text { Standardized } \\
\text { difference }\end{array}$ & $\begin{array}{l}\text { Gained } \\
\text { Medicaid } \\
N=4140\end{array}$ & $\begin{array}{l}\text { Continuously } \\
\text { uninsured } \\
N=4140\end{array}$ & $p$ value $^{\dagger}$ & $\begin{array}{l}\text { Standardized } \\
\text { difference }\end{array}$ \\
\hline $\begin{array}{l}\text { Smoking status at } \\
\text { baseline }\end{array}$ & & & $<0.001$ & 0.118 & & & 0.83 & 0.005 \\
\hline Every day smoker & $\begin{array}{l}5727 \\
(96.5)\end{array}$ & $8807(94.0)$ & & & $\begin{array}{l}3959 \\
(95.6)\end{array}$ & $3955(95.5)$ & & \\
\hline Some day smoker & $208(3.5)$ & $564(6.0)$ & & & $181(4.4)$ & $185(4.5)$ & & \\
\hline
\end{tabular}

Bold $=$ absolute standardized difference $\geq 0.1$

*Additional variables were included in the model to achieve optimal prediction of the propensity score: primary language, number of quit records prebaseline, number of departments in primary health center, number of primary care departments in primary health center, number of adult patients in primary health center, whether primary health center provides multidisciplinary care

${ }^{\dagger}$ Chi square test

${ }^{*}$ Includes Spanish language speakers regardless of recorded ethnicity

quite significant in this smaller group $(\mathrm{aOR}=1.29,95 \%$ CI: $0.99,1.67)$. Among those with more follow-up visits, the odds of quitting were $22 \%$ higher for those who gained Medicaid $(\mathrm{aOR}=1.22$, $95 \% \mathrm{CI}$ : $1.05-1.42)$; there were no significant between-group differences in quit rates among patients with $<6$ follow-up visits.

To further explore the relationships between quitting smoking and smoking cessation assistance, we conducted withingroup analyses to determine: 1) whether having a smoking cessation medication order documented was associated with higher odds of quitting compared to no documented smoking cessation order; and 2) whether patients with $\geq 6$ follow-up visits had higher quit rates compared to patients with $<6$ visits. As expected, having a smoking cessation medication order resulted in higher odds of quitting smoking for both groups (newly insured: aOR $=2.00,95 \% \mathrm{CI}: 1.69-2.37$; uninsured: $\mathrm{aOR}=1.90,95 \% \mathrm{CI}: 1.50-2.41$ ), and patients with more visits had higher odds of quitting than patients with fewer visits (newly insured: $\mathrm{aOR}=2.86,95 \% \mathrm{CI}$ : 2.36-3.45; uninsured: $\mathrm{aOR}=2.60,95 \% \mathrm{CI}$ : 2.16-3.12).

\section{DISCUSSION}

To our knowledge, this is the first study to use longitudinal EHR data from CHCs to examine the impact of gaining Medicaid coverage on ordering of smoking cessation medications and quit status. Over 24 months of follow-up, patients who gained Medicaid received smoking medication orders and quit smoking at higher rates than those who remained uninsured. The newly insured also had more follow-up visits. It is likely that both increased access to medications and to primary care influenced the improved quit rates for several reasons. Regardless of insurance status, smoking cessation medication orders were associated with an almost twofold higher quit rate. Higher medication order rates; however, do not tell the whole story because newly insured patients who did not have a smoking cessation medication ordered still had significantly higher quit rates than the uninsured. This, coupled with the findings that the odds of quitting were higher among patients with more visits, and that the insured cohort had more visits than the uninsured, suggests that increased access to care via insurance coverage is also a significant contributing factor. Increased access to primary care could result in more opportunities for receipt of other smoking cessation assistance, such as smoking cessation counseling or referral for such services; however, even among patients with higher utilization, the newly insured had higher odds of quitting than the uninsured. Although we were unable to capture counseling/referrals, we hypothesize that this could be indicative of more Medicaid-covered smoking cessation counseling services provided during these visits. This finding supports other research that has shown a combination of counseling and medications to be most efficacious for successful smoking cessation. ${ }^{9,36}$

Our findings among a population of $\mathrm{CHC}$ patients are similar to those reported in cross-sectional and treatmentbased studies in other primary care settings. Further, they are consistent with studies that have limited analyses to the associations between insurance coverage and smoking cessation assistance among patients with smoking-related diseases. ${ }^{37-39}$ A recent study reported that Medicaid spent over $\$ 39$ billion on smoking-related medical services in 2010; Medicare and Medicaid together covered approximately half of the $\$ 170$ billion spent annually on smoking-attributable healthcare among adults in the US, and the majority of these costs are associated with inpatient services. ${ }^{40}$ Our results suggest that Medicaid coverage can increase the odds of smoking cessation 
Table 2. Visits and Smoking Outcomes Among Current Smokers Who Gained Medicaid vs. Uninsured Comparison Patients

\begin{tabular}{|c|c|c|c|}
\hline & $\begin{array}{l}\text { Gained } \\
\text { Medicaid } \\
N=4140\end{array}$ & $\begin{array}{l}\text { Continuously } \\
\text { uninsured } \\
N=4140\end{array}$ & pvalue ${ }^{*}$ \\
\hline \multicolumn{4}{|l|}{ Primary care visits after } \\
\hline Median (IQR) & $7^{4,12}$ & $5^{3,8}$ & $<0.001^{\dagger}$ \\
\hline & $35(0.9)$ & $54(1.3)$ & $<0.001$ \\
\hline $3-5$ & $\begin{array}{l}1096 \\
(26.5)\end{array}$ & $1444(34.9)$ & \\
\hline $6-10$ & $\begin{array}{l}1216 \\
(29.4)\end{array}$ & $1119(27.0)$ & \\
\hline$>10$ & $\begin{array}{l}1267 \\
(30.6)\end{array}$ & $626(15.1)$ & \\
\hline Usual source of care & $\begin{array}{l}3516 \\
(84.9)\end{array}$ & $3629(87.7)$ & $<0.001$ \\
\hline \multicolumn{4}{|c|}{ Follow-up smoking assessments } \\
\hline Median (IQR) & $4^{2,8}$ & $3^{1,5}$ & $<0.001^{\dagger}$ \\
\hline 1 & $757(18.3)$ & $1259(30.4)$ & $<0.001$ \\
\hline $2-3$ & $\begin{array}{l}1074 \\
(25.9)\end{array}$ & $1284(31.0)$ & \\
\hline $4-5$ & $684(16.5)$ & $659(15.9)$ & \\
\hline$\geq 6$ & $\begin{array}{l}1625 \\
(39.3)\end{array}$ & $938(22.7)$ & \\
\hline $\begin{array}{l}\text { Smoking cessation } \\
\text { medication }^{\S} \text { ordered }\end{array}$ & $\begin{array}{l}1115 \\
(26.9)\end{array}$ & $477(11.5)$ & $<0.001$ \\
\hline $\begin{array}{l}\text { Follow-up smoking } \\
\text { status }\end{array}$ & & & $<0.001$ \\
\hline No change & $\begin{array}{l}3368 \\
(81.4)\end{array}$ & $3527(85.2)$ & \\
\hline $\begin{array}{l}\text { Reduced smoking } \\
\text { status }\end{array}$ & $86(2.1)$ & $63(1.5)$ & \\
\hline Quit & $686(16.6)$ & $550(13.3)$ & \\
\hline
\end{tabular}

within the primary care setting, which could significantly decrease rates of smoking-related diseases and their associated healthcare costs in the long-term.

Increased access to Medicaid via the ACA expansion, along with improved Medicaid coverage for tobacco treatment, may lead to increased primary care utilization and access to smoking cessation assistance. Patients who gained Medicaid had more primary care visits in the follow-up period than patients that remained uninsured; increased visit rates were associated with greater smoking status changes. Insurance coverage and access to primary care act interdependently to improve population health outcomes ${ }^{41-43}$; our study provides additional evidence supporting this link. Given the longstanding, major impacts of tobacco on mortality and morbidity, an increase in quit rates in a high-risk population could have major benefits on health outcomes and total healthcare costs. ${ }^{40}$

\section{Limitations}

Because we used EHR data, we only had follow-up smoking status for those patients who returned to the clinic, and therefore cannot determine the quit status of non-returning patients. Non-returning patients differed from the study sample on a number of baseline demographics (Online Appendix Table 1); the results of the study may not generalize to this group. Although we used propensity score matching to balance a range of baseline factors, there could be residual confounding due to unmeasured variables that could account, in part, for the observed differences. Our study was limited to an Oregon population of established CHC patients; thus, our results might not generalize to patients in other states or to adults who do not access healthcare services regularly. We did not assess if bupropion was prescribed for smoking cessation or depression; however, we used propensity scores to match patients on psychiatric diagnoses, including depression. It should be noted that we were only able to assess whether medications were prescribed, not whether the patients filled the prescriptions and took the medications. Finally, as mentioned previously, we were not able to reliably capture counseling services or referrals in the EHR during the study period. We hypothesize that the

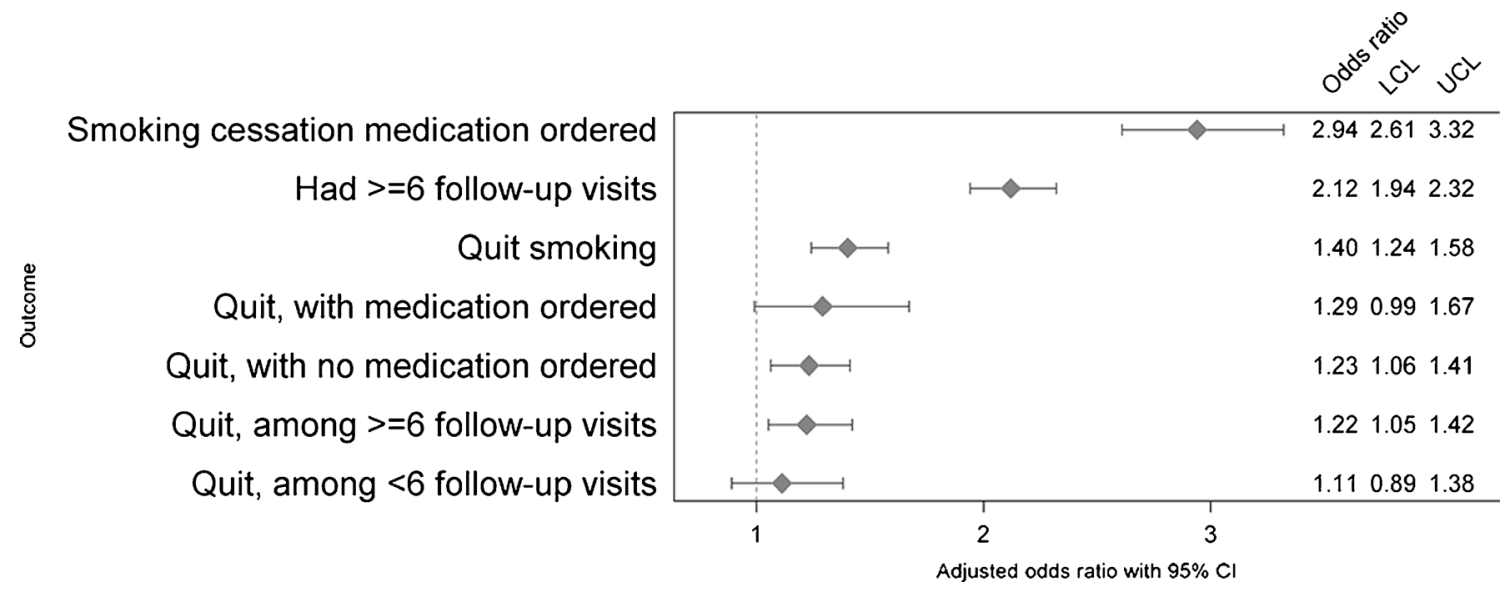

Figure 1 Odds ratios for outcomes related to smoking cessation (patients who gained Medicaid compared to continuously uninsured). Footnote: $\mathbf{L C L}=$ lower control limit; $\mathbf{U C L}=$ upper control limit. All odds ratios from generalized estimating equation models with clustering effect of propensity score-matched pair, adjusted for primary health center and having a usual source of care. Odds ratios by medication ordered from patient type*medication order interaction (interaction term was not significant in the model, $p=0.72$ ). Odds ratios by number of visits from patient type*visit strata interaction (interaction term was not significant in the model, $p=0.48$ ). 
higher quit rates among the newly insured not prescribed medications were due to increased access to other smoking cessation services; future research is warranted.

\section{CONCLUSIONS}

Returning CHC patients who smoked and gained Medicaid insurance coverage after being uninsured had increased visit rates and were significantly more likely to have a smoking cessation medication prescribed and to quit smoking over 24 months of follow-up than those who remained uninsured. These findings suggest that expanding Medicaid coverage could lead to a substantial decrease in smoking rates among vulnerable populations, thus reducing downstream detrimental effects caused by this life-threatening health behavior.

Acknowledgements: Contributors: The authors gratefully acknowledge the OCHIN network and the OCHIN Practice-Based Research Network. The corresponding author affirms that she has listed everyone who contributed significantly to the work represented in this study.

Funders: This study was supported by grants R01HL107647 from the National Heart, Lung, and Blood Institute, K23DA037453 from the National Institute on Drug Abuse, and RO1HSO24270 and K08HS021522 from the Agency for Healthcare Research and Quality. Prior presentations: The information in this paper was presented on 5 March 2016 at the 22nd Annual Society for Research on Nicotine \& Tobacco Meeting in Chicago, IL, and on 2 May 2016 at Oregon Health \& Science Research Week in Portland, OR.

Corresponding Author: Steffani R. Bailey, PhD; Department of Family MedicineOregon Health \& Science University, Portland, OR, USA (e-mail: bailstef@ohsu.edu).

\section{Compliance with Ethical Standards:}

Conflicts of Interest: Stephen P. Fortmann has received prior funding from Astra-Zeneca as a co-investigator on an observational study of hypertriglyceridemia in patients with diabetes. All other authors declare that they do not have a conflict of interest.

\section{REFERENCES}

1. Jamal A, Agaku IT, O'Connor E, et al. Current cigarette smoking among adults-United States, 2005-2013. MMWR Morb Mortal Wkly Rep. 2014;63(47): 1108-1112.

2. Centers for Disease Control and Prevention. Smoking-attributable mortality, years of potential life lost, and productivity losses-United States, 2000-2004. MMWR Morb Mortal Wkly Rep. 2008;57(45):12261228

3. Department of Health and Human Services. Office of Disease Prevention and Health Promotion. Healthly People 2020. https://www.healthypeople. gov. Accessed June 2, 2016.

4. Blackwell DL, Lucas JW, Clarke TC. Summary health statistics for U.S. adults: National Health Interview Survey, 2012. National Center for Health Statistics. Vital Health Stat. 2012;2014:10(260)

5. Land T, Warner D, Paskowsky M, et al. Medicaid coverage for tobacco dependence treatments in Massachusetts and associated decreases in smoking prevalence. PLoS One. 2010;5(3), e9770.

6. Greene J, Sacks RM, McMenamin SB. The impact of tobacco dependence treatment coverage and copayments in Medicaid. Am J Prev Med. 2014;46(4):331-336.

7. Bruen BK, Ku $\mathbf{L}, \mathbf{L u} \mathbf{X}$, et al. No evidence that primary care physicians offer less care to Medicaid, community health center, or uninsured patients. Health Aff (Millwood). 2013;32(9): 1624-1630.

8. National Association of Community Health Centers. United States Health Center Fact Sheet, 2012. Available at: http://www.nachc.org/client// US12.pdf. Accessed June 2, 2016.
9. Fiore MC, Jaén CR, Baker TB, et al. Treating tobacco use and dependence: 2008 update: clinical practice guideline. Rockville, MD: US Dept of Health and Human Services; Public Health Service; 2008.

10. Lancaster T, Stead L, Silagy C, et al. Effectiveness of interventions to help people stop smoking: findings from the Cochrane Library. BMJ. 2000;321(7257):355-358.

11. Hollis JF, Bills R, Whitlock E, et al. Implementing tobacco interventions in the real world of managed care. Tob Control. 2000;9(Suppl 1):I18-I24.

12. Chase EC, McMenamin SB, Halpin HA. Medicaid provider delivery of the 5A's for smoking cessation counseling. Nicotine Tob Res. 2007;9(11):10951101.

13. Thorndike AN, Regan S, Rigotti NA. The treatment of smoking by US physicians during ambulatory visits: 1994 2003. Am J Public Health. 2007;97(10): 1878-1883.

14. Ferketich AK, Khan Y, Wewers ME. Are physicians asking about tobacco use and assisting with cessation? Results from the 2001-2004 national ambulatory medical care survey (NAMCS). Prev Med. 2006;43(6):472-476.

15. Jamal A, Dube SR, Malarcher AM, et al. Tobacco use screening and counseling during physician office visits among adults-National Ambulatory Medical Care Survey and National Health Interview Survey, United States, 2005-2009. MMWR Morb Mortal Wkly Rep. 2012;61(Suppl):38-45.

16. Solberg LI, Maciosek MV, Edwards NM, et al. Repeated tobacco-use screening and intervention in clinical practice: health impact and cost effectiveness. Am J Prev Med. 2006;31(1):62-71.

17. McAfee T, Babb S, McNabb S, et al. Helping smokers quit-opportunities created by the Affordable Care Act. N Engl J Med. 2015;372(1):5-7.

18. Ku L, Bruen BK, Steinmetz E, et al. Medicaid tobacco cessation: big gaps remain in efforts to get smokers to quit. Health Aff (Millwood). 2016;35(1):62-70.

19. Boyle RG, Solberg LI, Magnan S, et al. Does insurance coverage for drug therapy affect smoking cessation? Health Aff (Millwood). 2002;21(6):162-168.

20. Cokkinides VE, Ward E, Jemal A, et al. Under-use of smoking-cessation treatments: results from the National Health Interview Survey, 2000. Am J Prev Med. 2005;28(1):119-122.

21. Schauffler HH, McMenamin S, Olson $\mathbf{K}$, et al. Variations in treatment benefits influence smoking cessation: results of a randomised controlled trial. Tob Control. 2001;10(2):175-180.

22. Reda AA, Kotz D, Evers SM, et al. Healthcare financing systems for increasing the use of tobacco dependence treatment. Cochrane Database Syst Rev. 2012;6:Cd004305.

23. Baicker K, Finkelstein A. The effects of Medicaid coverage-learning from the Oregon experiment. N Engl J Med. 2011;365(8):683-685.

24. DeVoe JE, Marino M, Gold R, et al. Community health center use after Oregon's randomized medicaid experiment. Ann Fam Med. 2015; 13(4):312-320.

25. Marino M, Bailey SR, Gold R, et al. Receipt of preventive services after Oregon's randomized medicaid experiment. Am J Prev Med. 2016;50(2):161-170

26. Oregon Department of Human Services, Programs DoMA. Oregon Health Plan Annual Report: Medicaid and State Children's Health Insurance Program Section 1115(a) Medicaid demonstration extension, 2008. Available at: http://www.oregon.gov/oha/healthplan/DataReportsDocs / FFY\%202008\%20Annual\%20Report.pdf. Accessed June 2, 2016.

27. Singleterry J, Jump Z, Lancet E, et al. State medicaid coverage for tobacco cessation treatments and barriers to coverage - United States, 2008-2014. MMWR Morb Mortal Wkly Rep. 2014;63(12):264-269.

28. Devoe JE, Gold R, Spofford M, et al. Developing a network of community health centers with a common electronic health record: description of the Safety Net West Practice-based Research Network (SNW-PBRN). J Am Board Fam Med. 2011;24(5):597-604.

29. Heintzman J, Bailey SR, Hoopes MJ, et al. Agreement of Medicaid claims and electronic health records for assessing preventive care quality among adults. J Am Med Inform Assoc. 2014;21(4):720-724.

30. Bailey SR, O'Malley JP, Gold R, et al. Receipt of diabetes preventive services differs by insurance status at visit. Am J Prev Med. 2015;48(2):229-233.

31. Rosenbaum PR, Rubin DB. The central role of the propensity score in observational studies for causal effects. Biometrika. 1983;70:41-55.

32. Coca-Perraillon M. Local and Global Optimal Propensity Score Matching. Proceedings of the SAS Global Forum 2007. Available at: http://www2.sas. com/proceedings/forum2007/185-2007.pdf. Accessed June 2, 2016.

33. Austin PC. A critical appraisal of propensity-score matching in the medical literature between 1996 and 2003. Stat Med. 2008:27:2037-2049.

34. Austin PC. Balance diagnostics for comparing the distribution of baseline covariates between treatment groups in propensity-score matched samples. Stat Med. 2009;28(25):3083-3107. 
35. Overall JE, Tonidandel S. Robustness of generalized estimating equation (GEE) tests of significance against misspecification of the error structure model. Biom J. 2004;46(2):203-213.

36. Siu AL. Behavioral and pharmacotherapy interventions for tobacco smoking cessation in adults, including pregnant women: U.S. preventive services task force recommendation statement. Ann Intern Med. 2015;163(8):622-634.

37. Tilert TJ, Chen J. Smoking-cessation advice to patients with chronic obstructive pulmonary disease: the critical roles of health insurance and source of care. Am J Prev Med. 2015;48(6):683-693.

38. Burcu M, Steinberger EK, Sorkin JD. Health care access and smoking cessation among cancer survivors: implications for the Affordable Care Act and survivorship care. J Cancer Surviv. 2016;10(1):1-10.
39. Huen KH, Chowdhury R, Shafii SM, et al. Smoking cessation is the least successful outcome of risk factor modification in uninsured patients with symptomatic peripheral arterial disease. Ann Vasc Surg. 2015;29(1):42-49.

40. Xu X, Bishop EE, Kennedy SM, et al. Annual healthcare spending attributable to cigarette smoking: an update. Am J Prev Med. 2015;48(3):326-333.

41. Kaiser Family Foundation. The Uninsured a primer 2013-4: How does lack of insurance affect access to health care? Nov 14, 2013. Available at: http://kff.org/report-section/the-uninsured-a-primer-2013-4-how-doeslack-of-insurance-affect-access-to-health-care/. Accessed March 8, 2016.

42. Wilper AP, Woolhandler S, Lasser $\mathbf{K E}$, et al. Health insurance and mortality in US adults. Am J Public Health. 2009;99(12):2289-2295.

43. Institute of medicine. Care without coverage, too little, too late. Washington, DC: The National Academies Press; 2002. 